\title{
Radiolabeled Monocyte Chemotactic Protein 1 for the Detection of Inflammation in Experimental Atherosclerosis
}

\author{
Dagmar Hartung ${ }^{1}$, Artiom Petrov ${ }^{1}$, Nezam Haider ${ }^{1}$, Shinichiro Fujimoto ${ }^{1}$, Francis Blankenberg ${ }^{2}$, Ai Fujimoto ${ }^{1}$, \\ Renu Virmani ${ }^{3}$, Frank D. Kolodgie ${ }^{3}$, H. William Strauss ${ }^{4}$, and Jagat Narula ${ }^{1}$ \\ ${ }^{1}$ University of California School of Medicine, Irvine, California; ${ }^{2}$ Stanford University Medical Center, Stanford, California; \\ ${ }^{3}$ International Registry of Pathology, Gaithersburg, Maryland; and ${ }^{4}$ Memorial Sloan-Kettering Cancer Center, New York, New York
}

Chemotactic peptides, such as Monocyte Chemotactic Protein 1 (MCP-1), play a key role in transendothelial migration of mononuclear cells during the development and progression of atherosclerotic disease. Because atherosclerotic plaques that are precursors of acute coronary events harbor abundant macrophage infiltration, we hypothesized that the detection of a high concentration of MCP-1 receptors on inflammatory cells should noninvasively identify vulnerable plaques. Methods: Atherosclerotic lesions were induced by balloon deendothelialization of the abdominal aorta, which was followed by a $0.5 \%$ cholesterol diet for 16 wk in 7 New Zealand White rabbits; 5 unmanipulated rabbits, fed normal chow for $16 \mathrm{wk}$, were used as controls. Radionuclide imaging was performed immediately after intravenous 99mTc-labeled MCP-1 administration and $3 \mathrm{~h}$ later. At the end of imaging session, aortas were explanted and submitted for estimation of quantitative MCP-1 uptake (in percentage injected dose per gram, \%ID/g) and pathologic characterization. Results: Atherosclerotic lesions were clearly visible in all hyperlipidemic animal $\gamma$-imaging. No tracer uptake was seen in the control rabbits. The mean quantitative MCP-1 uptake in atherosclerotic lesions was 4-fold higher than that of the aortic specimens from the control rabbits $(0.065 \pm 0.005$ vs. $0.016 \pm 0.006$; $P<0.0001)$. Histology confirmed a strong correlation between MCP-1 uptake and the number of macrophages in American Heart Association type II-IV lesions ( $r=0.87, P<0.0001)$. Conclusion: Noninvasive radionuclide imaging of inflammation is feasible by MCP-1 in experimentally induced atherosclerosis. It is proposed that detection of the extent of inflammation in advanced atherosclerotic plaques may allow identification of unstable plaques.

Key Words: inflammation; vulnerable plaque; cytokines; coronary artery disease

J Nucl Med 2007; 48:1816-1821

DOI: 10.2967/jnumed.107.043463

Received May 8, 2007; revision accepted Jul. 31, 2007

For correspondence or reprints contact: Artiom Petrov, PhD, University of California, Irvine, School of Medicine, C116 Medical Science I, Irvine, CA 92697.

E-mail: adpetrov@uci.edu

COPYRIGHT @ 2007 by the Society of Nuclear Medicine, Inc.

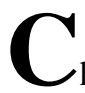

hemokines or chemotactic cytokines play a critical role in the inflammatory process in development and progression of atherosclerosis (1). Monocyte recruitment into the arterial wall in response to injury is a multistep process that involves reversible adhesion of monocytes to the endothelium, activation of monocytes, firm adherence, and, finally, migration to the subendothelial space through endothelial cell junctions (2-4). Monocyte Chemotactic Protein 1 (MCP-1) is overexpressed at the site of inflammation and mediates the transendothelial migration of mononuclear cells via CC chemokines receptor 2 (CCR-2) receptors expressed at their cell surface (4-6). In the hyperlipidemic state, activation of the MCP-1/CCR-2 pathway also induces adhesion molecules, proinflammatory cytokines, and chemokines and, thus, accelerates atherosclerosis (7-9). The early expression of MCP-1 by smooth muscle cells (SMC) and endothelial cells is responsible for the initial influx of monocytes into the vessel wall. The recruited monocytes/macrophages start to express MCP-1, triggering the continuing infiltration of macrophages in the neointima, suggesting a key role of MCP-1 in the progression of atherosclerosis.

Proinflammatory cytokines such as interleukin 1 (IL-1), interferon- $\gamma$ (INF- $\gamma$ ), and tumor necrosis factor- $\alpha$ (TNF- $\alpha)$ are known to increase the levels of CC chemokines (10). Other chemokines, produced at the site of inflammation, such as IL-1, TNF- $\alpha$, INF- $\gamma$ (10), RANTES (regulated on activation, T-cell expressed and secreted), MIP- $1 \alpha$ and $-\beta$ (macrophage inflammatory proteins $\alpha$ and $\beta)(11,12)$ or, more recently discovered MCP-4, ELC (EBI 1 ligand chemokine), PARC (pulmonary and activation regulated cytokine) (13), and IL-8 may also subsist as chemoattractants $(10,14)$ in atherogenesis and vascular remodeling $(15,16)$. MIP- $1 \alpha$ and $-\beta$, RANTES, and MCP- 4 are T-cell chemoattractants expressed in the more advanced atherosclerotic lesion (13). Unlike them, PARC has a specificity to attract naïve, resting T-cells, and IL- 8 facilitates a firm adhesion of monocytes to endothelium. Monocytes, once resident 
within the subintimal layer, transform to macrophages and eventually develop into foam cells by internalizing oxidized low-density lipoprotein (LDL) mediated by expression of scavenger receptors (I).

MCP-1 is a low-molecular-weight (9-15 kDa) monomeric peptide (17), which is predominantly expressed by endothelial cells $(18,19)$ and macrophages $(20)$. Vascular injury leads to selective MCP-1 expression on the endothelial cells or secretion of soluble MCP-1 (21). Circulating MCP-1 facilitatesin addition to monocyte migration and activation - upregulation of the MCP-1/CCR-2 receptors for this peptide. Because MCP-1 receptor is predominantly expressed by infiltrating macrophages, we hypothesized that radiolabeled MCP-1 should help target MCP-1 receptor-bearing cells in atherosclerotic lesions for noninvasive imaging. Because inflammation is one of the most important determinants of plaque vulnerability, it is expected that imaging of inflammation would allow development of preventive strategies.

\section{MATERIALS AND METHODS}

\section{Radiolabeling of MCP-1}

Recombinant human MCP-1, expressed in Escherichia coli, was derivatized with the nicotinic acid analog hydrazinonicotinamide (HYNIC; Theseus Imaging Corp.). Each vial of HYNIC-MCP-1 provided by Theseus Imaging contained $40 \mathrm{mM}$ ammonium acetate and $100 \mathrm{mM}$ tricine, $\mathrm{pH}$ 6. For radiolabeling, $50-100 \mu \mathrm{L}$ of ${ }^{99 \mathrm{~m}} \mathrm{Tc}-$ labeled sodium pertechnetate $(1,110 \mathrm{MBq}$ [30 mCi] $)$ were added to the protein vial. Then, $1 \mathrm{~mL}$ of $0.9 \%$ sodium chloride solution was added to the stannous tricine vial, and the vial was gently swirled until the lyophilized contents were dissolved. Immediately after dissolving, $20 \mu \mathrm{L}$ were withdrawn from the stannous tricine solution and added to the protein vial. After a 30-min incubation at room temperature, instant thin-layer chromatography was performed and the radiopurity of $>95 \%$.

\section{MCP-1 Receptor Expression on Macrophages and Binding of Radiolabeled MCP-1}

The radiolabeled MCP-1 was incubated with THP-1 monocytes (human monocytic leukemia cell line) and SMC cultured from the median layer of the aorta of New Zealand White (NZW) rabbits in minimum essential medium $/ 20 \%$ fetal calf serum. SMC of passages $3-5$ were used for the experiment. For the binding assay, $6 \times 10^{5}$ cells per well (THP-1; SMC) were placed in 12-well culture plates. Phorbol 12-myristate 13-acetate (PMA; $10 \mathrm{ng} / \mathrm{mL}$ ) was added to half of the THP-1 and SMC wells and incubated overnight to activate the cells. For controls, PMA was not added to the remaining half of the THP-1 and SMC wells. Cells were washed and resuspended in serum-free medium, which was followed by addition of ${ }^{99 \mathrm{~m}}$ Tc-labeled MCP-1 in a final volume of $1 \mathrm{~mL}$. After incubation for $15 \mathrm{~min}, 1 \mathrm{~h}$, and $4 \mathrm{~h}$ at $37^{\circ} \mathrm{C}$, wells were washed 3 times with phosphate-buffered saline (PBS)/bovine serum albumin (BSA). Cells were solubilized with $1 \mathrm{~mL}$ of $0.1 \%$ sodium dodecyl sulfate in $\mathrm{H}_{2} \mathrm{O}$ and counted for radioactivity in an automatic Wallace $\gamma$-counter (Perkin Elmer Wallace Inc.); data were expressed as counts per minute (cpm).

\section{Animal Model of Atherosclerosis}

Of the total of 12 rabbits included in this study, atherosclerotic lesions were experimentally induced in 7 by deendothelialization of the abdominal aorta, which was followed by a high-cholesterol diet. The remaining 5 unmanipulated rabbits were fed normal rabbit chow for $16 \mathrm{wk}$ and used as control animals.

For the induction of atherosclerotic lesions, male NZW rabbits (2.5-3.5 kg; Millbrook Breeding Laboratories) were started on a high-cholesterol diet containing $0.5 \%$ cholesterol and $6 \%$ peanut oil 1 wk before deendothelialization of the abdominal aorta as described previously (22). After anesthesia with a mixture of ketamine and xylazine (100 mg/mL, 10:1 [v/v]; 1.5-2.5 mL subcutaneously), the right femoral artery was surgically exposed. A 4-French Fogarty embolectomy catheter (12-040-4F; Edwards Lifesciences LLC) was introduced through an arteriotomy site, advanced in the aorta up to the level of the diaphragm, inflated to a pressure of $3 \mathrm{psi}$, and pulled antegrade to the bifurcation of the aorta for endothelial denudation. Three such passes were made. After removing the catheter, the femoral artery was ligated, the incision site was closed, and the animals were returned to cages. The high-cholesterol, highfat diet was continued for an additional $15 \mathrm{wk}$. This protocol conforms to the Guide for the Care and Use of Laboratory Animals by the U.S. National Institutes of Health (NIH Publication no. 85-23, revised 1996) and has been approved by the Institutional Laboratory Animal Care and Use Committee.

\section{Noninvasive Imaging Using ${ }^{99 m}$ Tc-MCP-1}

${ }^{99 m}$ Tc-MCP-1 (333 $\left.\pm 44 \mathrm{MBq}\right)$ was administered intravenously in all rabbits. Images in the left lateral decubitus position were obtained immediately and 1,2 , and $3 \mathrm{~h}$ after the administration of the radioligand using a $\gamma$-camera (Vertex PLUS; ADAC Laboratories) equipped with a low-energy, parallel-hole collimator. The images were acquired, centered at the $140-\mathrm{keV}$ photopeak of ${ }^{99 \mathrm{~m}} \mathrm{Tc}$ with a symmetric $15 \%$ window using a $128 \times 128$ matrix, as described previously (23). Planar images of the whole rabbits were obtained for $15 \mathrm{~min}$. After imaging, animals were sacrificed with an overdose of sodium pentobarbital $(120 \mathrm{mg} / \mathrm{kg})$. The aortas were harvested and the explanted aortas were imaged for $30 \mathrm{~min}$ by laying flat on the $\gamma$-camera. Aortas were then segmented at 1 -cm intervals and weighed; radioactivity was counted in an automatic well-type $\gamma$-counter (Perkin Elmer Wallace Inc.) for calculation of the percentage total injected dose per gram tissue $(\% \mathrm{ID} / \mathrm{g})$. Aortas were then preserved for histologic and immunohistochemical investigations. Tissue samples of lungs, heart, liver, spleen, kidneys, and stomach were also harvested, rinsed in saline, weighed, and $\gamma$-counted, and the results were expressed as the percentage injected dose per gram tissue $(\% \mathrm{ID} / \mathrm{g})$.

\section{Histolopathogic Characterization of Atherosclerotic Lesions}

As described earlier (22), one half of every aortic segment was snap frozen and the other half was fixed with $N$-(2-hydroxyethyl) piperazine- $N$ '-(2-ethanesulfonic acid) (HEPES)-buffered $4 \%$ formalin for paraffin embedding and further processing. The tissue was then dehydrated in a graded series of ethanol. Each segment was subdivided into 3 equidistant sections and embedded on-edge in paraffin. Serial 4- $\mu$ m-thick sections were cut and mounted on charged slides (Superfrost; Fisher). Tissue sections were stained with hematoxylin and eosin and Movat pentachrome elastin stain. Atherosclerotic lesions were characterized according to criteria established by the American Heart Association (AHA); only type II-IV lesions were observed (24-26).

Immunohistochemistry was performed by standard staining procedures as described previously (22). Briefly, for cellular char- 
acterization, sections were deparaffinized in xylene and treated with $0.3 \%$ hydrogen peroxide for $20 \mathrm{~min}$ to inactivate endogenous peroxides. Tissue sections were then incubated in a protein-free block (Dako) $(10 \mathrm{~min})$ to inhibit the nonspecific binding of primary antibody. SMC were identified using a primary antibody against $\alpha$-actin isotypes (HHF, 1:20, overnight; Enzo), and macrophages were localized using the marker RAM-11 (Dako) (1:200, $1 \mathrm{~h})$. In addition, the MCP-1 antibody (PharMinger, 1:10, overnight; Becton Dickinson Co.) was used for characterization of endogenous and exogenous MCP-1 localization. Primary antibodies were targeted with a biotinylated link antibody directed against mouse immunoglobulin using a peroxidase-based kit (LSAB; Dako). Immunostains were visualized (red-reaction product) by a 3-amino-9-ethyl carbazole (AEC) substrate-chromogen system (Dako) and counterstained with Gill's hematoxylin. The specificity of primary antibody was confirmed both by omitting the primary antibody and by substituting isotype-matched nonspecific antibodies. Immunostaining was observed under an Axiovert-200 inverted microscope (Carl Zeiss), and images were acquired with a Zeiss Axiocam high-resolution digital color camera $(1,300 \times 1,030$ pixels $)$ using Axiovision 3.1 software. Digital images were analyzed using Image-pro Plus Version 5.0 software (Media Cybernetics). The percentage of immunopositive area (immunopositive area/total image area $\times 100$ ) was determined for all of the markers studied by averaging several images per section that covered most-to-all of the plaque regions. All quantitative comparisons for a given marker were performed on sections stained simultaneously per group. Digital images were obtained using the same settings, and the segmentation parameters were constant within a range for a given marker and experiment.

\section{Statistical Analysis}

All results are expressed as the mean $\pm \mathrm{SD}$. To determine the statistical significance of differences between 2 groups, comparisons were made with a 2-tailed Student $t$ test for unpaired data. A $P$ value $<0.05$ was considered to be statistically significant.

\section{RESULTS}

\section{Ligand-Binding Analyses}

SMC formed a single cell layer attached to the well surface. On the other hand, THP-1 cells grew in cell suspension but attached to the well surface on PMA activation. After incubation of ${ }^{99 \mathrm{~m}} \mathrm{Tc}-\mathrm{MCP}-1$ with THP-1 and SMC cells, and PMA-treated THP-1 cells for $15 \mathrm{~min}, 1 \mathrm{~h}$, and $4 \mathrm{~h}$, radioactivity was counted. MCP-1 uptake in the untreated THP-1 cells $(20,493 \pm 256 \mathrm{cpm})$ was significantly higher than that of SMC $(10,312 \pm 266 \mathrm{cpm})$ at $4 \mathrm{~h}(P=0.007)$ (Fig. 1). PMA-treated THP-1 cells demonstrated a 2-fold increase in MCP-1 uptake at $4 \mathrm{~h}(43,988 \pm 1,084 \mathrm{cpm} ; P<0.003)$.

\section{Radionuclide Imaging of Atherosclerotic Lesions}

By noninvasive $\gamma$-imaging, the abdominal atherosclerotic lesions were visualized best by $3 \mathrm{~h}$ in hyperlipidemic rabbits (Fig. 2). The uptake was predominantly localized to the infradiaphragmatic aorta. No uptake was seen in the unmanipulated control animals. The \%ID/g uptake of the radioligand confirmed the imaging results (Fig. 2). The quantitative MCP-1 uptake was significantly higher in the lesion areas of the abdominal aorta in atherosclerotic rabbits compared with that of the abdominal aortic segments of unmanipulated

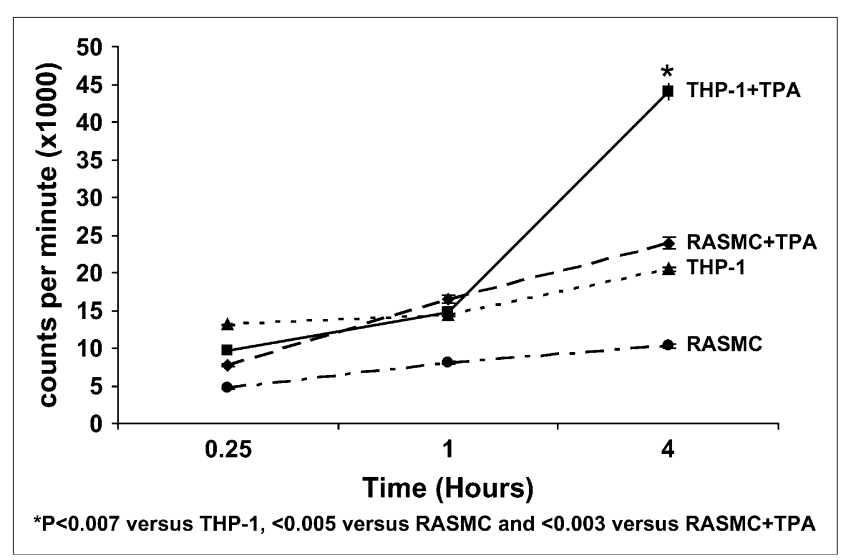

FIGURE 1. $99 \mathrm{mTC}$ MCP-1 uptake in activated and nonactivated SMC and macrophages (in counts/min $\times 1,000$ ) in culture. Uptake increases significantly when monocytes (THP-1 cells) are activated with PMA. RASMC = rat aortic smooth muscle cells.

animals $(0.065 \pm 0.005$ vs. $0.016 \pm 0.006 ; P<0.0001)$. The MCP-1 accumulation in atherosclerotic lesions was 4-fold higher than that of the corresponding abdominal aortic region of the control animals.

The biodistribution of ${ }^{99 \mathrm{~m}} \mathrm{Tc}-\mathrm{MCP}-1$ in nontarget organs was maximum in renal cortex $(3.34 \pm 0.75)$, spleen $(0.39 \pm$ 0.14 ), and liver $0.12 \pm 0.04)$ Radiation burden was evident in lung tissue $(0.07 \pm 0.01)$ and myocardium $(0.04 \pm 0.01)$.

\section{Histologic and Immunhistochemical Characteristics}

The atherosclerotic lesions of the hyperlipidemic animals were classified primarily as AHA type II-IV lesions (24-26). The lesions with the highest MCP-1 uptake showed an intense subintimal macrophage accumulation, contained only few smooth muscle cells, and showed low collagen content (Fig. 3). These lesions were predominantly classified as AHA type IV lesions. A strong correlation between MCP-1 uptake and the number of lesion macrophages was observed $(r=$ $0.87 ; P<0.0001$ ) (Fig. 4). There was a statistically insignificant negative correlation of MCP-1 with the SMC prevalence in the atherosclerotic lesions. The staining for MCP-1 colocalized with the macrophages; the MCP-1 antibody reacts with both radiolabeled MCP-1 administered exogenously and endogenous MCP-1.

\section{DISCUSSION}

The present study demonstrates the feasibility of noninvasive imaging of plaque inflammation with ${ }^{99 \mathrm{~m}} \mathrm{Tc}$-labeled MCP-1 in a diet-injury rabbit model of atherosclerosis. A 4-fold higher uptake of radiolabeled MCP-1 was observed in the lesion as compared with that of the unaffected areas of the aorta. There was direct correlation between the magnitude of MCP-1 uptake and the extent of inflammation in the neointima. MCP-1 clearly colocalized with macrophage distribution. However, there was no apparent correlation between the subintimal SMC population and MCP-1. In vitro exper- 

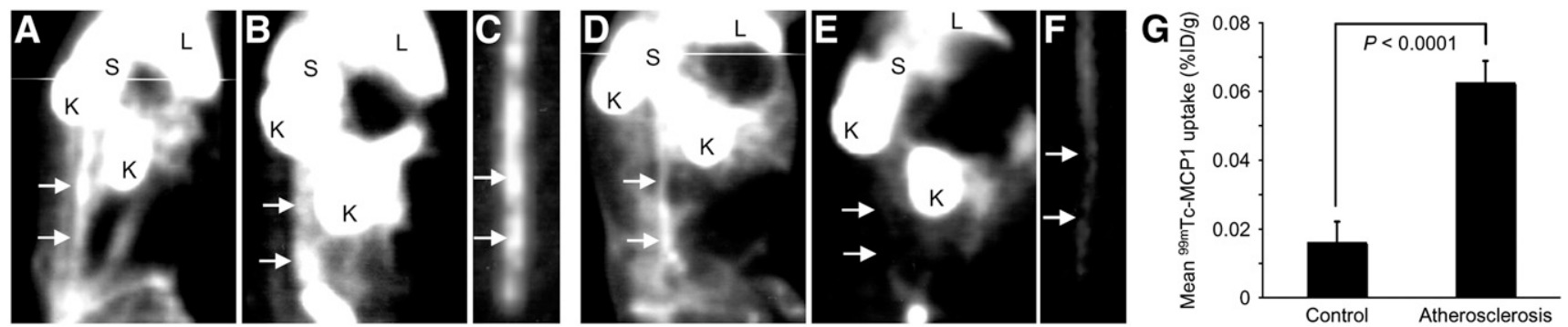

FIGURE 2. Noninvasive imaging of MCP-1 receptor expression in experimentally induced atherosclerosis with radiolabeled MCP-1. Images were obtained in both atherosclerotic $(A-C)$ and control (nonatherosclerotic, $D-F)$ rabbits. $(A-C)$ Planar $\gamma$-images of atherosclerotic rabbit. (A) Image obtained immediately after intravenous MCP-1 administration outlines aortic blood-pool activity (arrows). (B) At $3 \mathrm{~h}$ after radiotracer administration, significant radiotracer accumulation is evident in abdominal aorta (arrows). (C) Ex vivo image of explanted aorta confirms in vivo evidence of MCP-1 uptake (arrows). (D-F) Planar $\gamma$-images of control rabbit. (D) Aortic blood pool is seen at time of intravenous MCP-1 injection (arrows). (E) Image shows lack of MCP-1 uptake in region of abdominal aorta, as denoted by arrows in normal rabbit with no atherosclerotic lesions. (F) Ex vivo aortic image of control animal demonstrates absence of MCP-1 uptake (arrows). $\mathrm{L}=$ liver; $\mathrm{S}=$ spleen; $\mathrm{K}=$ kidney. (G) Bar graphs show quantitative 99mTc MCP-1 uptake within abdominal aortas of atherosclerotic and control animals represented as mean \%ID/g \pm SD. ${ }^{99 m T C-M C P-1}$ uptake $(\% \mathrm{ID} / \mathrm{g})$ was significantly higher in atherosclerotic animals $(P<0.0001)$ compared with that of control animals.

iments revealed that the MCP-1 uptake occurred preferentially in the monocytes after they were converted to the macrophage phenotype in culture. The number of chemotactic receptors on the surface of monocytes is upregulated from about 3,000 per cell in the resting state to $>60,000$ per cell by activation through MCP-1 (27). In fact, only a $20 \%$ increase of CCR-2 receptors on the cell surface doubles the chemotactic response of THP-1 cells to MCP-1 $(28,29)$. MCP-1 has an affinity of about $10^{-9} \mathrm{M}$ for the CCR-2 chemokine receptor (30). Upregulation of the CCR-2 receptor on monocytes in response to a higher circulating MCP-1 level has been demonstrated. CCR-2 receptors are expressed predominantly at the cell surface of activated monocytes and offer substrate for easy targeting by appropriately labeled exogenous targeting agents (30).

${ }^{125}$ I-Labeled MCP-1 has been used previously for the identification of lesional monocytes and macrophages in experimental atherosclerosis by autoradiography (31). The highest ${ }^{125} \mathrm{I}-\mathrm{MCP}$ uptake was observed in lesions with the higher macrophage infiltration, and there was a direct
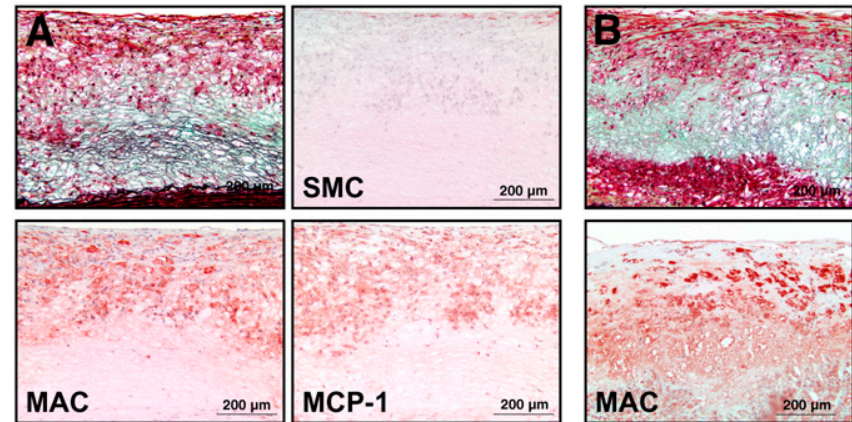

SMC
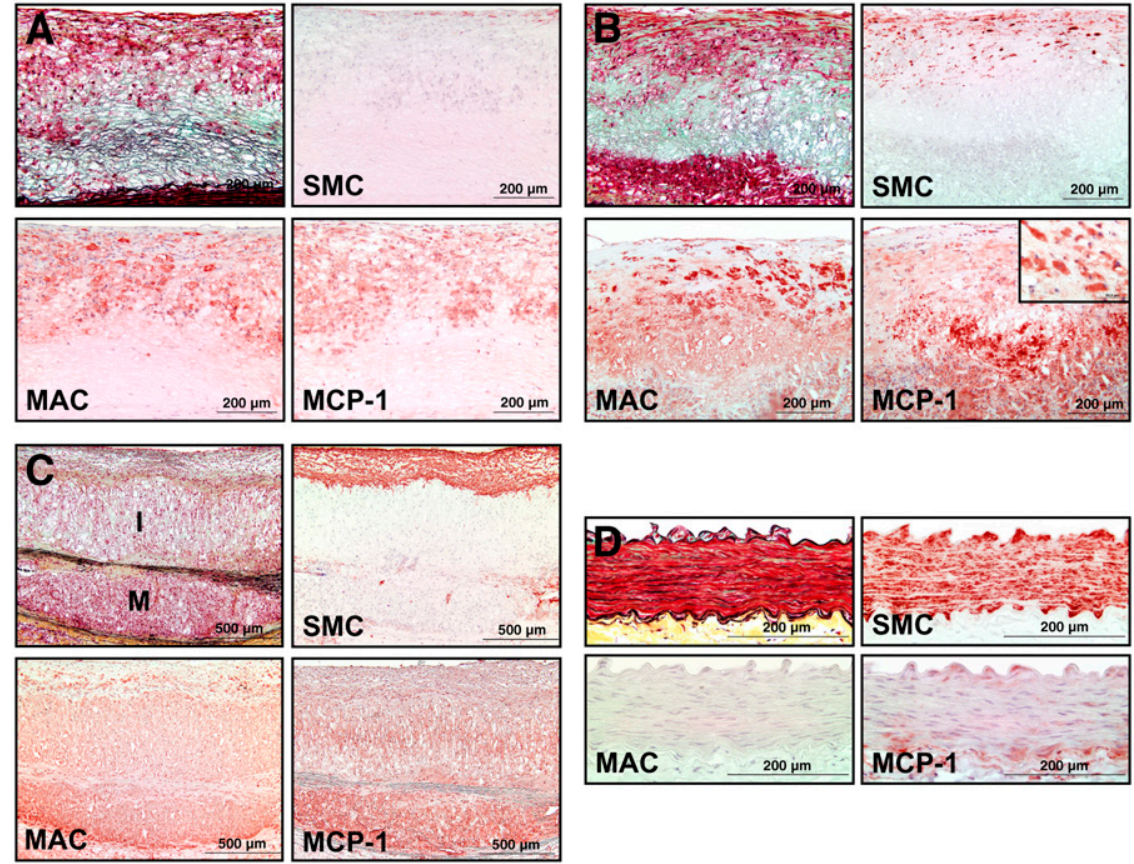

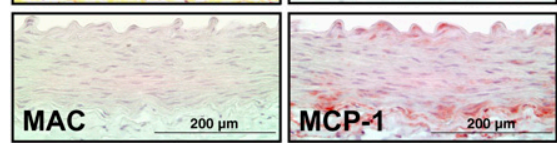

MAC
$200 \mathrm{\mu m}$

$\mathrm{MCP}-1$
FIGURE 3. Histologic and immunohistologic characterization of atherosclerotic plaques with increasing severity in comparison with nonatherosclerotic abdominal aorta in control rabbit. (A) Lesion composed predominantly of superficial macrophages overlying acellular area of extracellular matrix. Only a few smooth muscle cells are evident on surface of lesion. There is relatively intense staining for Monocyte Chemotactic Protein 1 (MCP-1) (rose-red reaction product) primarily near luminal border localized to areas rich in macrophages. (B) More advanced plaque consisting of macrophages, SMC, and underlying extracellular matrix. Immunostaining for MCP-1 is intense and localized primarily in deeper layers of lesion. Inset shows cytoplasmic staining of MCP-1 in cells resembling macrophages. (C) Lesion shows medial dissection with intense macrophage infiltration in intimal (I) and medial (M) layers with overlying SMC-rich fibrous cap. Immunostaining for $\mathrm{MCP}-1$ is diffusely seen throughout plaque, corresponding

to areas of macrophage infiltration. (D) Control vessel shows absence of macrophages, with MPC-1 present only in occasional cells near lumen and medial/adventitial borders. Histologic stain in each panel is Movat pentachrome. Immunostains are counterstained with Gill's hematoxylin; chromogen is 3-amino-9-ethyl carbazole (AEC). SMC = $\alpha$-actin smooth muscle; MAC = Ram 11 . 


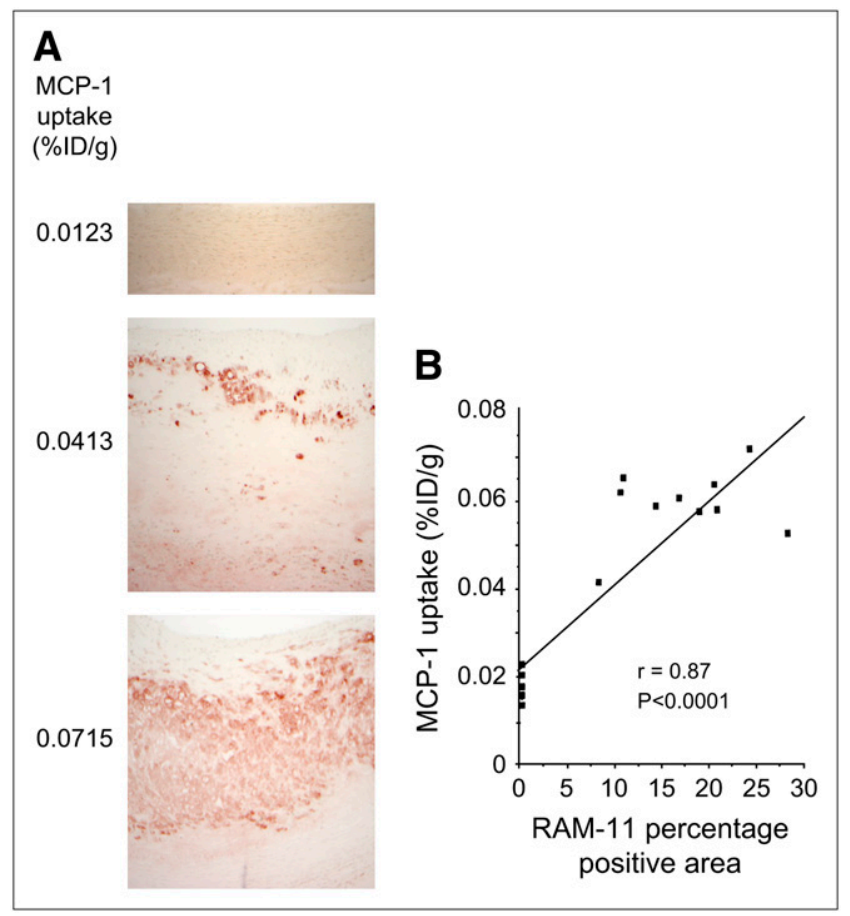

FIGURE 4. Extent of MCP-1 uptake and macrophage content in abdominal aorta. (A) Prevalence of macrophages as defined by RAM-11-positive area in neointima $(\times 100)$ is visibly higher in animal showing high uptake of radiolabeled MCP-1 (bottom). On the other hand, lower RAM-11-positive areas are seen in animal with low quantitative MCP-1 uptake (middle). Control aortic specimens show no RAM 11-positive areas (top). (B) Correlation between MCP-1 uptake and macrophage prevalence shows direct proportional relationship.

relationship between the number of RAM-11-positive macrophages per high-power field and the uptake of iodinated MCP-1. The present study describes incrementally the feasibility of noninvasive detection of increased MCP-1 uptake in the atherosclerotic lesions.

Expression of both MCP-1 and its monocyte receptor is upregulated early during the process of atherosclerotic lesion formation and persists into the advanced atherosclerotic state. Overexpression of MCP-1 in apolipoprotein E-deficient mice is known to result in accelerated atherogenesis through an increased number of macrophages and lipid accumulation in the lesion (9). On the other hand, LDL receptor-deficient mice with deletion of the MCP-1 gene develop resistance to the effects of a cholesterol-rich diet with substantial reduction in the extent of atherosclerosis (32), and CCR-2 receptor-deficient mice do not develop atherosclerosis (33). Furthermore, a close association between circulating MCP-1 and other markers of atherosclerosis in humans (34) has been observed in clinical biomarker studies, which support the previous belief that MCP-1 is involved in the initiation and progression of coronary atherosclerosis.

Various radionuclide imaging approaches have been investigated to identify the inflammatory component of the atherosclerotic lesions. Although radiolabeled autologous leukocytes were first reported in the imaging of atherosclerotic lesions (35), ${ }^{18} \mathrm{~F}-\mathrm{FDG}$ has been used most commonly $(36-40) .{ }^{18} \mathrm{~F}-\mathrm{FDG}$ is avidly taken up by cells with high metabolic activity and accumulates in macrophages in atherosclerotic vascular lesions. ${ }^{18} \mathrm{~F}-\mathrm{FDG}$ uptake in clinical carotid vascular disease has been shown to correlate with the extent of macrophage infiltration in carotid endarterectomy specimens (39) and resolves with statin treatment (37). ${ }^{18} \mathrm{~F}-$ FDG uptake, representative of plaque inflammation, is also higher in patients with the metabolic syndrome (38). On the other hand, radiolabeled IgG, and its Fc fragments (41), have been used to target Fc scavenger $\gamma$-receptors expressed by macrophages. The expression of receptors for chemotactic protein $(30,31)$ adhesion molecules $(42,43)$ may offer alternative targets for imaging. Furthermore, macrophages undergoing apoptosis have been successfully targeted with radiolabeled annexin A5 $(22,44)$. It is, therefore, possible to use multiple strategies for assessment of the extent of inflammation in atherosclerotic lesions. Prospective studies would be needed for defining the role of imaging inflammation in clinical practice. Because the extent of inflammation is closely linked to plaque instability, its noninvasive detection may be of clinical significance.

\section{CONCLUSION}

Noninvasive detection of inflammation in experimental atherosclerotic lesions is feasible using radiolabeled MCP-1. The uptake of MCP-1 correlated with the pathologically verified extent of macrophage infiltration in the plaque.

\section{ACKNOWLEDGMENT}

This study was supported by National Institutes of Health grant RO1 (HL 078681).

\section{REFERENCES}

1. Ross R. Atherosclerosis: an inflammatory disease. N Engl J Med. 1999;340: $115-126$.

2. Rollins BJ. Monocyte chemoattractant protein 1: a potential regulator of monocyte recruitment in inflammatory disease. Mol Med Today. 1996;5:198-204.

3. Valente AJ, Rozek MM, Sprague EA, Schwartz CJ. Mechanisms in intimal monocyte-macrophage recruitment: a special role for monocyte chemotactic protein-1. Circulation. 1992;86(suppl):III20-III25.

4. Yoshimura T, Leonard EJ. Identification of high affinity receptors for human monocyte chemoattractant protein-1 on human monocytes. J Immunol. 1990; 145:292-297.

5. Namiki M, Kawashima S, Yamashita T, et al. Local overexpression of monocyte chemoattractant protein-1 at vessel wall induces infiltration macrophages and formation of atherosclerotic lesion: synergism with hypercholesterolemia. Arterioscler Thromb Vasc Biol. 2002;22:115-120.

6. Butcher EC. Leukocyte-endothelial cell recognition: three (or more) steps to specificity and diversity. Cell. 1991;67:1033-1036.

7. Jiang Y, Beller DI, Frendl G, et al. Monocyte chemoattractant protein-1 regulates adhesion molecule expression and cytokine production in human monocytes. J Immunol. 1992;148:2423-2428.

8. Lu B, Rutledge BJ, Gu L, et al. Abnormalities in monocyte recruitment and cytokine expression in monocyte chemoattractant protein 1-deficient mice. $J$ Exp Med. 1998;187:601-608.

9. Aiello RJ, Bourassa PA, Lindsey S, et al. Monocyte chemoattractant protein-1 accelerates atherosclerosis in apolipoprotein E-deficient mice. Arterioscler Thromb Vasc Biol. 1999;19:1518-1525. 
10. Libby P. Current concepts of the pathogenesis of the acute coronary syndromes. Circulation. 2001;104:365-372.

11. Hayes IM, Jordan NJ, Towers S, et al. Human vascular smooth muscle cells express receptors for CC chemokines. Arterioscler Thromb Vasc Biol. 1998;18: $397-403$.

12. Wilcox JN, Nelken NA, Coughlin SR, Gordon D, Schall TJ. Local expression of inflammatory cytokines in human atherosclerotic plaques. J Atheroscler Thromb. 1994;1(suppl 1):S3-S10.

13. Reape TJ, Rayner K, Manning CD, et al. Expression and cellular localization of the CC chemokines PARC and ELC in human atheroscerotic plaques. Am J Pathol. 1999;154:365-374.

14. Libby P. Inflammation and thrombosis: the clot thickens. Circulation. 2001;105: 1718-1720.

15. Apostolopoulos J, Davenport P, Tipping PG. Interleukin-8 production by macrophages from atheromatous plaques. Arterioscl Thromb Vasc Biol. 1996;16: 1007-1012.

16. Wang N, Tabas I, Winchester R, Ravalli S, Rabbani LE, Tall A. Interleukin 8 is induced by cholesterol loading of macrophages and expressed by macrophage foam cells in human atheroma. J Biol Chem. 1996;271:8837-8842.

17. Yoshimura T, Yuhki N, Moore SK, Appella E, Lerman MI, Leonard EJ. Human monocyte chemoattractant protein-1 (MCP-1): full-length cDNA cloning, expression in mitogen-stimulated blood mononuclear leukocytes, and sequence similarity to mouse competence gene JE. FEBS Lett. 1989;244:487-493.

18. Rollins BJ, Yoshimura T, Leonard EJ, Pober JS. Cytokine-activated human endothelial cells synthesize and secrete a monocyte chemoattractant, MCP-1/JE. Am J Pathol. 1990;136:1229-1233.

19. Strieter RM, Wiggins R, Phan SH, et al. Monocyte chemotactic protein gene expression by cytokine-treated human fibroblasts and endothelial cells. Biochem Biophys Res Commun. 1989;162:694-700.

20. Nelken NA, Coughlin SR, Gordon D, Wilcox JN. Monocyte chemoattractant protein-1 in human atheromatous plaques. J Clin Invest. 1991;88:1121-1127.

21. Takahashi M, Masuyama J, Ikeda U, et al. Induction of monocyte chemoattractant protein-1 synthesis in human monocytes during transendothelial migration in vitro. Circ Res. 1995;76:750-757.

22. Kolodgie FD, Petrov A, Virmani R, et al. Targeting of apoptotic macrophages and experimental atheroma with radiolabeled annexin $\mathrm{V}$ : a technique with potential for noninvasive imaging of vulnerable plaque. Circulation. 2003;108: 3134-3139.

23. Hartung D, Sarai M, Petrov A, et al. Resolution of apoptosis in atherosclerotic plaque by dietary modification and statin therapy. J Nucl Med. 2005;46:20512056.

24. Stary HC, Blankenhorn DH, Chandler AB, et al. A definition of the intima of human arteries and of its atherosclerosis-prone regions: a report from the Committee on Vascular Lesions of the Council on Arteriosclerosis, American Heart Association. Arterioscler Thromb. 1992;12:120-134.

25. Stary HC, Chandler AB, Dinsmore RE, et al. A definition of advanced types of atherosclerotic lesions and a histological classification of atherosclerosis: a report from the Committee on Vascular Lesions of the Council on Arteriosclerosis, American Heart Association. Arterioscler Thromb Vasc Biol. 1995;15:1512-1531.

26. Stary HC, Chandler AB, Glasgov S, et al. A definition of initial, fatty streak, and intermediate lesions of atherosclerosis: a report from the Committee on Vascular Lesions of the Council on Atherosclerosis, American Heart Association. Arterioscler Thromb Vasc Biol. 1994;14:840-856.

27. Turner SJ, Domin J, Waterfield MD, Ward SG, Westwick J. The CC chemokine monocyte chemotactic peptide-1 activates both the class I p85/p110 phospha- tidylinositol 3-kinase and the class II PI3K-C2alpha. J Biol Chem. 1998;273: 25987-25995.

28. Tangirala RK, Murano K, Quehenberger O. Regulation of expression of the human monocyte chemotactic protein-1 receptor (hCCR2) by cytokines. J Biol Chem. 1997;272:8050-8056.

29. Han KH, Tangirala RK, Green SR, Quehenberger O. Chemokine receptor CCR2 expression and monocyte chemoattractant protein-1-mediated chemotaxis in human monocytes: a regulatory role for plasma LDL. Arterioscler Thromb Vasc Biol. 1998;18:1983-1991.

30. Blankenberg FG, Wen P, Dai M, et al. Detection of early atherosclerosis with radiolabeled monocyte chemoattractant protein-1 in prediabeteic Zucker rats. Pediatr Radiol. 2001;31:827-835.

31. Ohtsuki K, Hayase M, Akashi K, Kopiwoda S, Strauss HW. Detection of monocyte chemoattractant protein-1 receptor expression in experimental atherosclerotic lesions: an autoradiographic study. Circulation. 2001;104:203-208.

32. Gu L, Okada Y, Clinton SK, et al. Absence of monocyte chemoattractant protein-1 reduces atherosclerosis in low density lipoprotein receptor-deficient mice. $\mathrm{Mol}$ Cell. 1998;2:275-281.

33. Boring L, Gosling J, Cleary M, Charo IF. Decreased lesion formation in $\mathrm{CCR} 2^{-1-}$ mice reveals a role for chemokines in the initiation of atherosclerosis. Nature. 1998;394:894-897.

34. De Lemos JA, Morrow DA, Sabatine MS, et al. Association between plasma levels of monocyte chemoattractant protein-1 and long-term clinical outcomes in patients with acute coronary syndromes. Circulation. 2003;107:690-695.

35. Virgolini I, Muller C, Fitscha P, Chiba P, Sinzinger H. Radiolabelling autologous monocytes with 111-indium-oxine for reinjection in patients with atherosclerosis. Prog Clin Biol Res. 1990;355:271-280.

36. Dunphy MP, Freiman A, Larson SM, Strauss HW. Association of vascular ${ }^{18} \mathrm{~F}-$ FDG uptake with vascular calcification. J Nucl Med. 2005;46:1278-1284.

37. Tahara N, Kai H, Ishibashi M, et al. Simvastatin attenuates plaque inflammation: evaluation by fluorodeoxyglucose positron emission tomography. J Am Coll Cardiol. 2006;48:1825-1831.

38. Tahara N, Kai H, Yamagishi S, et al. Vascular inflammation evaluated by $\left[{ }^{18} \mathrm{~F}\right]-$ fluorodeoxyglucose positron emission tomography is associated with the metabolic syndrome. J Am Coll Cardiol. 2007;49:1533-1539.

39. Tawakol A, Migrino RQ, Bashian GG, et al. In vivo ${ }^{18} \mathrm{~F}$-fluorodeoxyglucose positron emission tomography imaging provides a noninvasive measure of carotid plaque inflammation in patients. J Am Coll Cardiol. 2006;48:1818-1824.

40. Rudd J, Myers K, Bansilal S, et al. FDG PET imaging of atherosclerotic plaque inflammation is highly reproducible: implications for atherosclerosis therapy trials. J Am Coll Cardiol. 2007;50:892-896.

41. Fischman AJ, Rubin RH, Delvecchio A. Imaging of atheromatous lesions in the iliac and femoral vessels: preliminary experience with In-111 IgG in human subjects [abstract]. J Nucl Med. 1989;30(suppl):817P.

42. Sadeghi MM, Schechner JS, Krassilnikova S, et al. Vascular cell adhesion molecule-1-targeted detection of endothelial activation in human microvasculature. Transplant Proc. 2004;36:1585-1591.

43. Ohtani H, Strauss HW, Southern JF, Tamatani T, Miyasaka M, Isobe M. Imaging of intercellular adhesion molecule-1 induction in rejecting heart: a new scintigraphic approach to detect early allograft rejection. Transplant Proc. 1993;25: 867-869.

44. Kietselaer BL, Reutelingsperger CP, Heidendal GA, Daemen M, Mess W, Hofstra L. Noninvasive detection of plaque instability with use of radiolabeled annexin A5 in patients with carotid-artery atherosclerosis. N Engl J Med. 2004; 350:1472-1473. 